\title{
Optimizing the start-up process of post-combustion capture plants by varying the solvent flow rate
}

\author{
Thomas Marx-Schubach ${ }^{1}$ Gerhard Schmitz ${ }^{1}$ \\ ${ }^{1}$ Institute of Engineering Thermodynamics, Hamburg University of Technology, Germany, \\ \{thomas.marx, schmitz\}@tuhh. de
}

\begin{abstract}
This paper presents an optimization of the start-up process of a post-combustion carbon capture plant (PCC-plant) by varying the solvent flow rate. In a first optimization run the start-up time is minimized. In a second optimization run the overall carbon capture rate during the start-up process is maximized. The results show the great potential of the optimization, as the start-up time can be reduced from $\Delta t=4650 \mathrm{~s}$ in the reference case to $\Delta t=2840 \mathrm{~s}$ in the optimized scenario.
\end{abstract}

Keywords: optimization, start-up, absorption process, carbon capture, process engineering

\section{Introduction}

To stop global warming, ambitious goals have to be set. At the United Nations Climate Change Conference in Paris in 2015 a limit for the global temperature increase was set to $1.5^{\circ} \mathrm{C}$ above pre-industrial levels (United Nations, Framework Convention on Climate Change, 2016). To achieve this goal the carbon dioxide emissions have to be reduced significantly. One possibility is the usage of the Carbon Capture and Storage (CCS) technology, which means that the carbon dioxide is removed from the flue gas and can be stored in underground formations. As reported by the International Energy Agency (IEA) it is estimated that CCS can have a $17 \%$ share on the $\mathrm{CO}_{2}$ reduction in the year 2035 (IEA (International Energy Agency), 2013).

Furthermore, the increasing amount of renewable energies will lead to more fluctuations of net load in the power grid (Montañés et al., 2016). This will impose new challenges and operational requirements on the flexibility of thermal power plants as start-up and shutdown sequences and the operation at partial load will become still more important in the future.

The start-up process of a power plant is a time consuming and complex operation. When a carbon capture plant is coupled to a power plant the start-up procedure becomes even more complex. As power plants will start up and shutdown even more frequently in the future, the minimization of the start-up time is desirable. Hence, there is a requirement of reducing the start-up time. This can be achieved by optimizing the start-up time using dynamic models. As a first step an approach for the optimization of a post-combustion carbon capture plant is given in this paper. At the moment the common start-up procedure of carbon capture plants is only based on experience.

Many different studies focus on the dynamic simulation of post-combustion carbon capture plants (Bui et al., 2014). Some studies present the optimization of a capture plant but most of them focus only on the steady state and full time operation. Since the full time operation of carbon capture plants might not be economically feasible, also the optimization of dynamic operation periods will become important in the future (Bui et al., 2014). There are also studies available dealing with the optimal control of the process, e.g. (Panahi and Skogestad, 2011), (Åkesson et al., 2012), (Lin et al., 2011), (Luu et al., 2015) and (Mechleri et al., 2017). However, to the authors knowledge the studies do not concentrate on modelling start-up and shut down procedures of the whole plant. In order to close this gap, a model which can describe the start-up process is developed and a first approach for an optimization of the process is presented.

\section{Process description}

Several processes are available for the post-combustion capture (PCC) of $\mathrm{CO}_{2}$ from power plant flue gases such as membrane processes, adsorption and absorption processes. One possibility is to remove the $\mathrm{CO}_{2}$ in a gas scrubbing unit using aqueous solutions of different alkylamines as a solvent, also known as the amine gas treating process. A process flow diagram of this process is shown in figure 1. The flue gas first enters a flue gas cooler and is compressed in a blower. The cooled flue gas enters the absorption unit at the bottom of the column. The solvent flows countercurrent to the flue gas down to the column sump. $90 \%$ of the $\mathrm{CO}_{2}$ is chemically absorbed by the solvent. Afterwards the rich solvent is preheated in a heat exchanger and pumped to the stripper. The solvent is evaporated in a reboiler using steam from the power plant to provide the required energy for solvent regeneration. Desorption takes place in the stripper and the almost pure $\mathrm{CO}_{2}$ (up to $99.9 \%$ ) leaves the plant through a condenser. The regenerated solvent is pumped back to the absorption unit. Many different solvent additives, primary, secondary and tertiary amines, can be used. In this case the used solvent is a 30 wt.-\% monoethanolamine (MEA) aqueous solution. 


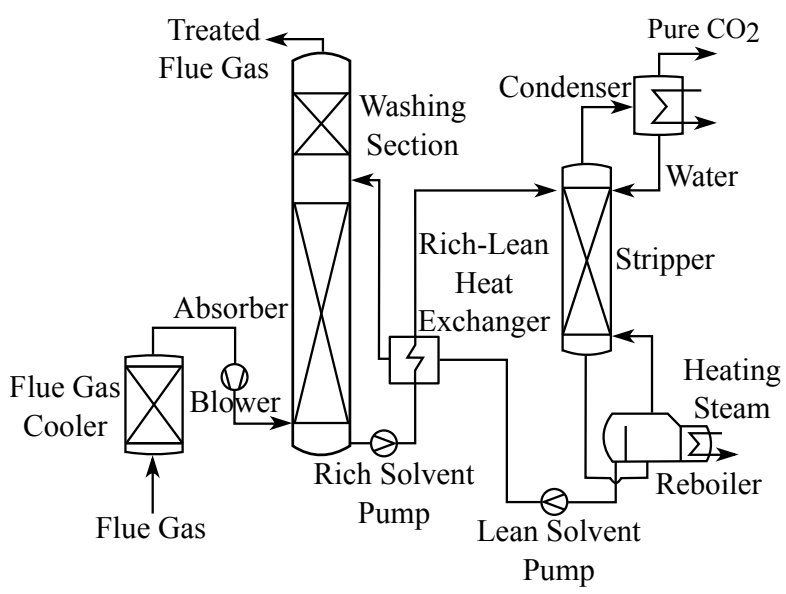

Figure 1. Process flow diagram of a post-combustion capture plant (Wellner et al., 2016).

The columns are usually filled with structured or random packings of different types.

The start up process of the plant is described in the following. At the beginning, the columns are in a cold and empty state. The process is started with the activation of the solvent pumps. Simultaneously, the other pumps for the washing sections, flue gas cooler and condenser are switched on. When the packing units inside the columns are wetted the heating steam can be supplied in the reboiler and the flue gas compressor can be switched on. The start up process is completed when the capture rate in the absorber reaches its nominal value of $90 \%$. To achieve this goal, the thermal and chemical equilibrium in the absorption unit has to be reached and the stripper has to attain his operation temperature of approximately $120^{\circ} \mathrm{C}$ to ensure a sufficient regeneration of the solvent. The heat up process of the stripper takes the most time and is therefore the limiting factor for the start up time. The stripper heats up in two different ways.

1. The solvent is evaporated in the reboiler and the vapour enters the stripper at the lower part of the column.

2. The solvent which remains in the stripper sump is pumped through a counter flow heat exchanger and heats up the rich solvent that enters the stripper at the top.

A reduction of the start-up time can be performed by selecting the right solvent flow trajectory, which is not trivial, since the variation of the solvent flow rate has counteracting effects on the heat up rate. When the solvent flow rate is increased the temperature in the reboiler is reduced and it takes more time for the solvent to reach the boiling point. On the downside, the residence time of the solvent in the stripper sump decreases leading to a faster increase of the solvent temperature in the stripper sump. Decreasing the solvent flow rate leads to the opposite result. Therefore, the optimal trajectory of the solvent flow rate has to be found numerically using a model of the post combustion carbon capture plant.

\section{Model description}

In this section the developed model and the used model libraries are described briefly. A detailed model for the dynamic simulation of the described process is developed within the ThermalSeparation library in Modelica (Dietl, 2012; Joos et al., 2009). The Optimization is performed with the commercial Optimization Library developed by DLR (A. Pfeiffer, 2012).

\subsection{Model libraries}

The ThermalSeparation library is a free Modelica library intended to describe separation processes such as absorption and rectification processes in Modelica. It can be used for the dynamic simulation of tray and packed columns with different levels of detail. More information about the library can be found in (Dietl, 2012; Joos et al., 2009).

The Optimization library is a commercial library for many different optimization tasks such as Trajectory Optimization, Realtime Optimization and Model Optimization. The library is released with Dymola and works only in this simulation environment. In this article the Trajectory Optimization is used. Further information about the library is given in (A. Pfeiffer, 2012).

\subsection{Start-up model}

A model of a post-combustion $\mathrm{CO}_{2}$ capture plant, that can describe the start-up process, is developed at the Institute of Engineering Thermodynamics in Modelica using the ThermalSeparation library and validated with data of a pilot plant.

The pilot plant is located in Heilbronn, Germany and can handle a nominal flue gas stream of $1500 \mathrm{~m}^{3} / \mathrm{h}$. The absorber has a height of $40 \mathrm{~m}$ and the stripper of $30 \mathrm{~m}$. Both columns have a diameter of $0.6 \mathrm{~m}$ and are filled with the random packing type VSP-25 (VFF GmbH, 2016). The most relevant parameters of the nominal operation point are listed in table 1. More information about the pilot plant can be found in (Rieder and Unterberger, 2013).

The pilot plant is modelled using a first principle approach where the columns are axially divided into stages. The vapour and liquid mass and energy balances are solved separately in each stage. For the heat- and mass transfer across the phase boundary a equilibrium approach is used. The chemical reaction of carbon dioxide with the solvent is considered. It is assumed that the reaction takes place only in the liquid phase. More information about the model and the underlying assumptions can be found in (Wellner et al., 2016).

The most important input variables of the pilot plant are the solvent flow rate $\dot{V}_{l i q}$, the molar flue gas flow rate $\dot{N}_{f g}$ 
Table 1. Main parameters of pilot plant.

\begin{tabular}{ll}
\hline Parameter & Value \\
\hline Flue gas volume flow rate & $1500 \mathrm{~m}^{3} / \mathrm{h}$ \\
$\mathrm{CO}_{2}$ concentration flue gas & $12.3 \mathrm{~mol}-\%$ \\
Flue gas temp. absorber inlet & $40{ }^{\circ} \mathrm{C}$ \\
Solvent flow rate & $5.3 \mathrm{~m}^{3} / \mathrm{h}$ \\
Solvent temp. absorber inlet & $35^{\circ} \mathrm{C}$ \\
MEA concentration & $30 \mathrm{wt} .-\%$ \\
Stripper pressure & $2 \mathrm{bar}$ \\
$\mathrm{CO}_{2}$ product temperature & $23^{\circ} \mathrm{C}$ \\
$\mathrm{CO}_{2}$ target capture rate & $90 \%$ \\
\hline
\end{tabular}

and the heat flow rate to the reboiler $\dot{Q}_{\text {reb }}$.

While the solvent flow rate and the heat flow rate are controllable within their limits, the flue gas flow rate depends on the firing output of the power plant. The flue gas flow rate is only controllable when a part of the flue gas is bypassed. In an usual start up scenario the solvent flow rate and the heat flow in the reboiler are set to their steady state values during the whole start-up process. However, this results in a very high start-up time. Hence, there is a high potential for optimization.

Simulation and validation results of the validation startup scenario are shown in the following. At the beginning of the start-up procedure, the solvent pumps are switched on until the $\mathrm{CO}_{2}$ concentration in the solvent is homogenized in the whole plant and until the columns are wetted. This step was not included in the optimization, since the solvent pumps should be operated at maximum flow rate to wet the columns as fast as possible. Hence, the focus of the optimization lies on the second part of the process when the flue gas flow enters the absorber.

In Figure 2 the carbon capture rate during the second part of the start-up process in the model and in the pilot plant is illustrated. The $\mathrm{CO}_{2}$ capture rate is defined in the

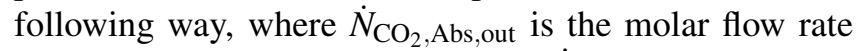

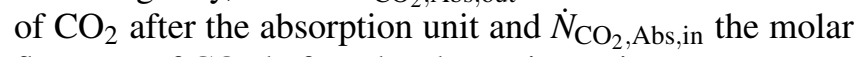
flow rate of $\mathrm{CO}_{2}$ before the absorption unit.

$$
X_{\mathrm{CO}_{2}}=1-\frac{\dot{N}_{\mathrm{CO}_{2}, \mathrm{Abs}, \text { out }}}{\dot{N}_{\mathrm{CO}_{2}, \mathrm{Abs}, \text { in }}}
$$

At $t=0 \mathrm{~s}$ the flue gas flow to the absorber is started. The steam supply in the reboiler starts later at $t=240 \mathrm{~s}$ due to the time delay in the steam generator and the steam cycle of the power plant. All incoming $\mathrm{CO}_{2}$ is absorbed until the solution is saturated. Therefore, the $\mathrm{CO}_{2}$ capture rate is nearly $100 \%$ at the beginning and drops quickly after approximately $2000 \mathrm{~s}$ since the solvent in the absorption unit is saturated with $\mathrm{CO}_{2}$ and is not regenerated in the stripper yet. The capture rate in the pilot plant can only be calculated from this point on because the $\mathrm{CO}_{2}$ concentration at the absorber outlet has not been measured correctly before. Due to the increasing temperature in the stripper, the $\mathrm{CO}_{2}$ loading of the solvent in the stripper decreases

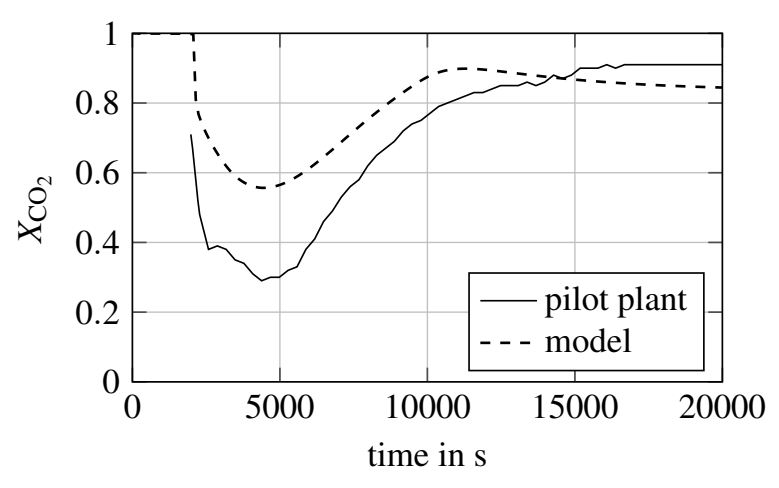

Figure 2. Validation start-up strategy - $\mathrm{CO}_{2}$ capture rate

and the capture rate rises slowly to its steady state value.

After $t=2000 \mathrm{~s}$ the results of the model show a significant deviation from the measurements of the pilot plant. One reason is that the columns are modelled based on a equilibrium approach which means that the heat and material transport equations in each stage are neglected. Another reason is the deviation of the measuring instruments, since some measured values, e.g. the $\mathrm{CO}_{2}$-concentration at the absorber outlet, are far from their nominal values. However, the agreement of the dynamic behaviour between the model and the pilot plant is very good except the small overshoot after $t=10000 \mathrm{~s}$. The start-up process is completed when the plant is capable of keeping a capture rate of $90 \%$.

Figure 3 shows the transient behaviour of the stripped $\mathrm{CO}_{2}$ mass flow rate downstream the condenser for the same time period. The measured values are also compared with the simulated ones.

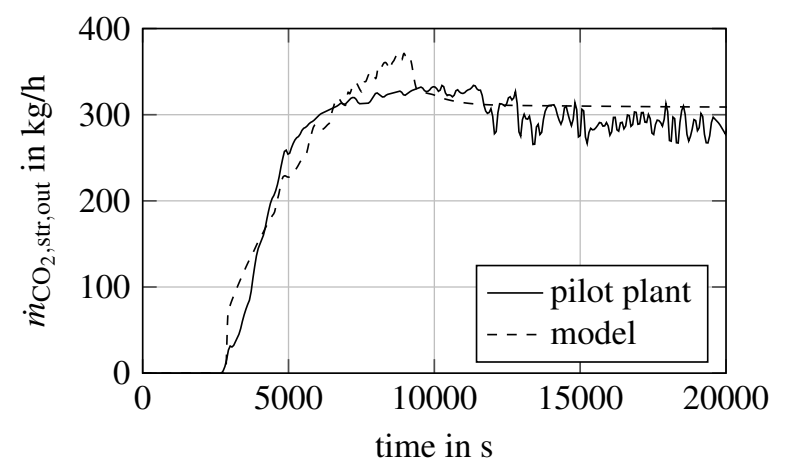

Figure 3. Validation start-up strategy $-\mathrm{CO}_{2}$ mass flow downstream the stripper

The simulation data shows a very good agreement with the measurement data except the overshoot in the simulation data at the end of the start-up process. The overshoot can be explained by the model assumption that the steam in the stripper condenses in every stage where the boiling temperature is not reached yet. In reality the $\mathrm{CO}_{2}$ leaving the stripper is loaded with steam especially at high temperatures close to the boiling point. This energy loss leads to a smaller amount of stripped $\mathrm{CO}_{2}$ in the pilot plant at 
Table 2. General criteria in optimization runs

\begin{tabular}{lcl}
\hline Variable name & Constraint & Type \\
\hline Reboiler temperature & $T_{R e b} \leq 125^{\circ} \mathrm{C}$ & at any time \\
Liquid hold-up & $V_{l i q, R e b} \geq 0.35 \mathrm{~m}^{3}$ & at any time \\
Solvent flow rate & $0.0002 \mathrm{~m}^{3} / \mathrm{s} \leq \dot{V}_{l i q} \leq 0.002 \mathrm{~m}^{3} / \mathrm{s}$ & at any time \\
\hline
\end{tabular}

the end of the start-up process. It can be seen that the amount of stripped $\mathrm{CO}_{2}$ in the stripper is nearly the same in the model an in the pilot plant in the timespan between approximately $t=2000 \mathrm{~s}$ and $t=8000 \mathrm{~s}$. However, the amount of captured $\mathrm{CO}_{2}$ is much higher in the model in the same timespan. Therefore, if one assumes a correct initial amount and loading of the solvent, the overall $\mathrm{CO}_{2}$ mass balance in the pilot plant is not fulfilled, which leads to the assumption of a certain measuring error. Furthermore, the time limiting component during the start-up process is the stripper. The model can therefore be used for optimization purposes.

According to the simulation, the start-up time in the validation case is $\Delta t=9440 \mathrm{~s}$, which is very high.

\section{Optimization setup}

In this section the simplification of the model and the implementation of the optimization run is presented.

The model used for validation is simplified in a first step in order to reduce the computation time and improve the robustness of the model. The following simplifications of the model were made:

- The intermediate cooling unit in the absorber was neglected.

- The flue gas scrubbing units before and after the absorber were removed

Furthermore, the total amount of solvent in the pilot plant is specifically high compared to other postcombustion capture plants (Wellner et al., 2016). Therefore, the total amount of solvent in the pilot plant is reduced by $50 \%$ to get more commonly results. Thermal stresses were neglected in the reboiler as the start-up process is most of all limited due to the high amount of solvent in the stripper sump. Nevertheless, thermal stresses should be taken into account in the future to prove this assumption. An overview of the model used for the optimization is shown in Figure 5. The gas streams are marked orange, the solvent streams are marked blue. The flue gas stream entering the absorber and the heat flow rate are implemented using a ramp from the Modelica Standard library as source signal. The solvent flow rate can be set by using an input connector which is connected to the lean solvent pump. The input connector is used for the optimization. The rich solvent pump is controlled keeping the filling level of the absorber sump at a setpoint of 2 metres.

As optimization method a Single Shooting Technique approach is used. The trajectories are approximated with B-splines of order 3. For the construction of the splines 10 equidistant knots, so called de Boor points, are used in the optimization runs. They can be used as tuner variables in the optimization method. Using more knots would lead to a more accurate solution but the optimization would take more time. Optimizations with different amounts of knots were carried out. The result is that 10 knots are a good compromise between accuracy and simulation time. An example of the construction of the trajectory using Bsplines is shown in figure 4. The optimization problem is solved by using the gradient based Sequential Quadratic Programming (SQP) algorithm. The algorithm is effective for solving nonlinear optimization problems with linear constraints. The constraints are essential for the optimization problem. Therefore an algorithm which is capable of solving optimization problems with constraints has to be used.

Generally, different optimization algorithms for nonlinear optimization with constraints can be used, such as Random search, interior-point method. A overview of possible optimization algorithms can be found in (Rao, 2009). In this paper a gradient based method was used as these algorithms converge faster in general. The SQP algorithm is sufficient for solving the optimization problem. A disadvantage is that the algorithm can only find local optima.

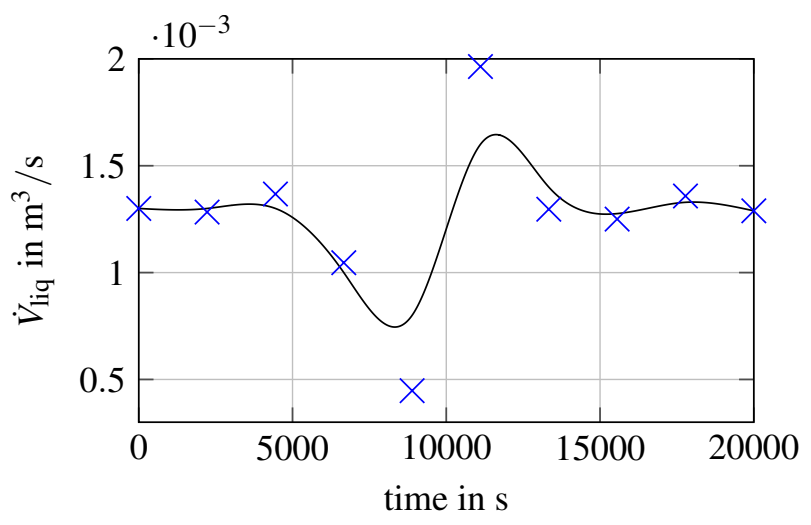

Figure 4. Example of the construction of B-splines

A general optimization problem with equality and in- 


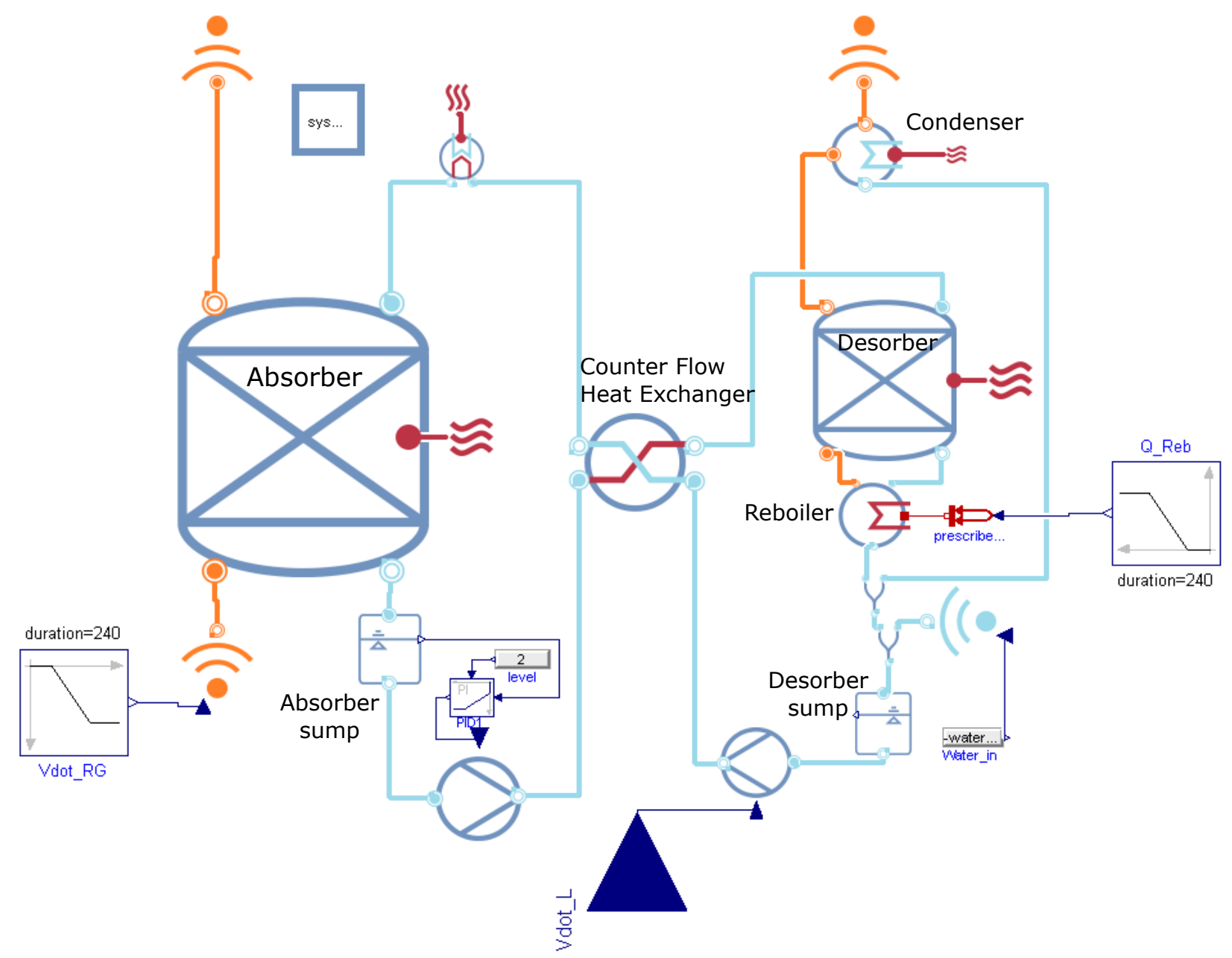

Figure 5. Simplified Modelica model of the carbon capture plant in Dymola simulation environment.

equality constraints can be defined in the following way.

$$
\begin{array}{r}
\text { minimize } \mathrm{f}(\mathrm{x}) \\
\text { in subject to } \\
g_{i} \leq a \\
h_{i}=b
\end{array}
$$

Before the optimization is started, the minimization criteria and the different constraints have to be defined. In the first optimization the start-up time is minimized. In a second optimization the mean value of the $\mathrm{CO}_{2}$ capture rate during the start-up process is maximized.

The optimal trajectory of the solvent flow rate has to satisfy many constraints to ensure that the plant is operated within the permissible operation range. Two of them are used in both optimization runs. First, the temperature in the reboiler may not exceed $125^{\circ} \mathrm{C}$ at any time since the degradation of the solvent increases significantly at higher temperatures. Second, the hold-up in the reboiler may not fall below $0.35 \mathrm{~m}^{3}$ to provide that the heat pipes are covered with solvent.

The SQP solver can only handle inequality constraints in the following form.

$$
g_{i} \leq b
$$

As the hold-up in the reboiler may not fall below a specific value, the inverted hold-up is used as constraint. For the reboiler temperature and the hold up a Maximum-Block of the Optimization-Library is used to make sure that the temperature or liquid hold-up do not exceed their limits during the whole simulation time as the optimization algorithm only evaluates the last value of the criteria. The general constraints are summarized in table 2 .

The other two input variables, the flue gas flow and the heat flow rate to the reboiler, are kept constant during the optimization runs at their steady state values.

The optimization runs are executed on a windows server with two Intel ${ }^{\circledR}$ Xeon E5-2650 v3 CPU and 128 GB memory. To improve the simulation time, the integration of the model is parallelized by the Optimization-library. The maximum number of threads is set to 8 .

\section{Reference start-up scenario}

As mentioned in section 3.2 the implementation of the start-up process is based on experience. The current startup process is performed by setting all manipulated variables to their steady-state values, which results in a high 
start-up time. As presented in section 4 the model structure was changed slightly and the total amount of solvent was reduced. Therefore, the validation scenario shown in section 3.2 can not be used as a reference for the optimization. The start-up time decreases significantly due to the reduction of the total amount of solvent. For this reason a new reference scenario has to be defined by simulating the reduced model. The carbon capture rate in the reference scenario is shown in figure 6 .

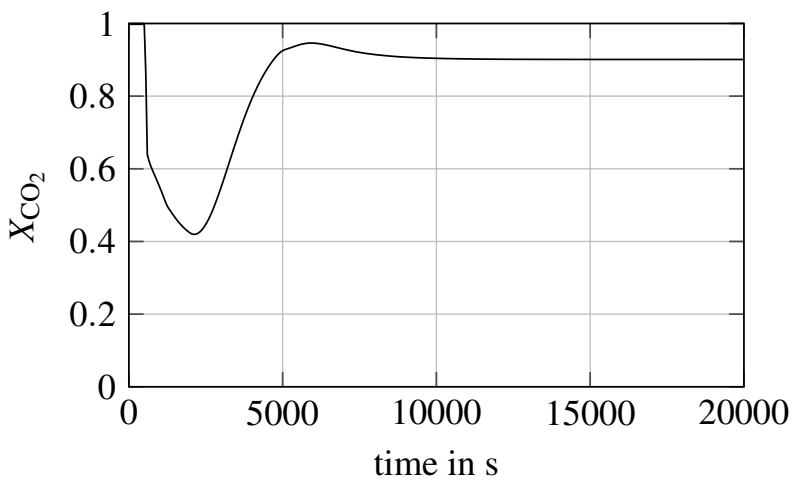

Figure 6. Reference start-up scenario - capture rate

All manipulated variables are kept at their steady state values during the whole start-up process in the reference case. The start-up time in the reference scenario is $\Delta t=$ $4650 \mathrm{~s}$, which is reduced in the following optimization scenario.

\section{Minimizing the start-up time}

In this section the minimization of the start-up time should be achieved by finding the optimal solvent flow trajectory (optimization 1). For the optimization run additional constraints and criteria have to be set.

First, the end of the start-up process has to be specified by using constraints. Therefore, it is defined that the carbon capture rate has to be at least $90 \%$ at the end of the optimization. However, this constraint does not guarantee that the plant can keep a stable capture rate of $90 \%$. To make sure that the solvent is sufficiently regenerated at the end of the start-up process, a constraint for the solvent loading in the stripper sump is added. The solvent loading is defined in equation 4 and is the ratio of the amount of $\mathrm{CO}_{2}$ and MEA in the solvent.

$$
\alpha=\frac{N_{\mathrm{CO}_{2}}}{N_{\mathrm{MEA}}}
$$

The solvent loading in the stripper sump has to reach the steady-state value of $\alpha=0.184 \mathrm{~mol}_{\mathrm{CO}_{2}} / \mathrm{mol}_{\mathrm{MEA}}$ to ensure a stable carbon capture rate of $90 \%$. As the library only handles criteria in the form presented in equation 3 the capture rate was also inverted in the model. The additional criteria are shown in table 3.
Table 3. Additional criteria in optimization run 1

\begin{tabular}{lcl}
\hline Variable name & Criteria & Type \\
\hline Capture rate & $X_{\mathrm{CO}_{2}} \geq 0.9$ & end point \\
Solvent loading & $\alpha_{\mathrm{str}, \mathrm{sump}}=0.184 \frac{\mathrm{mol}_{\mathrm{CO}_{2}}}{\mathrm{~mol}_{\mathrm{MEA}}}$ & end point \\
Start-Up time & $t$ & minimize
\end{tabular}

The resulting solvent flow rate trajectory of the first optimization run is shown in Figure 7.

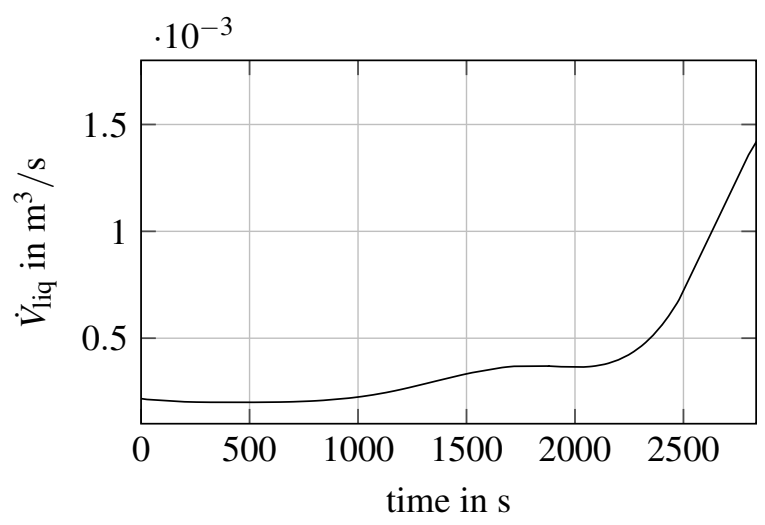

Figure 7. Minimized start-up time - solvent flow rate

As in the reference start-up scenario presented in chapter 3.2 the flue gas flow to the absorber starts at $t=0 \mathrm{~s}$. The steam supply in the reboiler starts also later at $t=240 \mathrm{~s}$ due to the time delay in the steam generator and the steam cycle of the power plant. The solvent flow trajectory during the start-up process can be split up into three phases. At the beginning of the optimal start-up process the solvent flow rate is at the minimum flow rate of $0.0002 \mathrm{~m}^{3} / \mathrm{s}$. The minimum solvent flow rate leads to a maximum of the reboiler heat up rate. The reboiler temperature is shown in figure 8 .

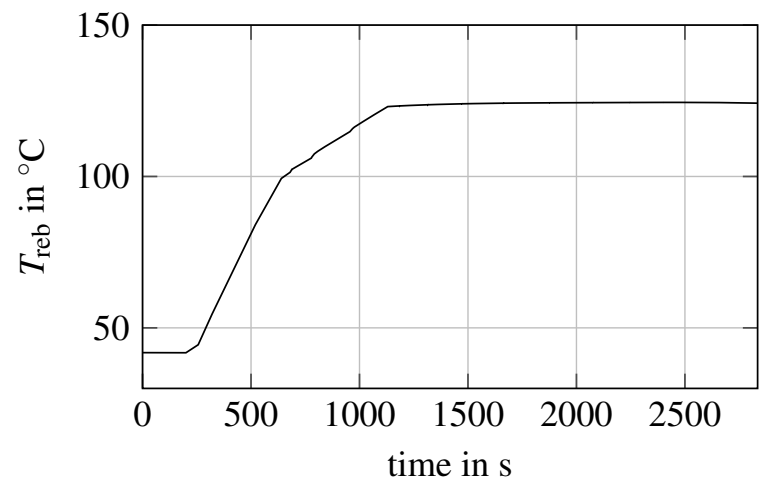

Figure 8. Minimized start-up time - Reboiler temperature

When the reboiler reaches its operation temperature of approximately $120^{\circ} \mathrm{C}$ the solvent flow rate rises to $0.00037 \mathrm{~m}^{3} / \mathrm{s}$. This happens for two reasons. On the one 
hand the solvent flow rate has to be increased to prevent that the temperature in the reboiler exceeds the limit of $125^{\circ} \mathrm{C}$. On the other hand the increasing solvent flow rate leads to a smaller residence time in the stripper sump in order to achieve a higher heat up rate of the solvent in the stripper sump. As soon as the stripper reaches the operation temperature the solvent flow rate increases continuously to increase the capture rate. At a capture rate of $90 \%$ a PID controller is switched on. The controller uses the capture rate of $90 \%$ as a setpoint and the solvent flow rate as the manipulated variable. This results in a small oscillation of the solvent flow rate after the controller is switched on. The start-up process is finished at this point.

Figure 9 shows the carbon capture rate during and after the start-up process.

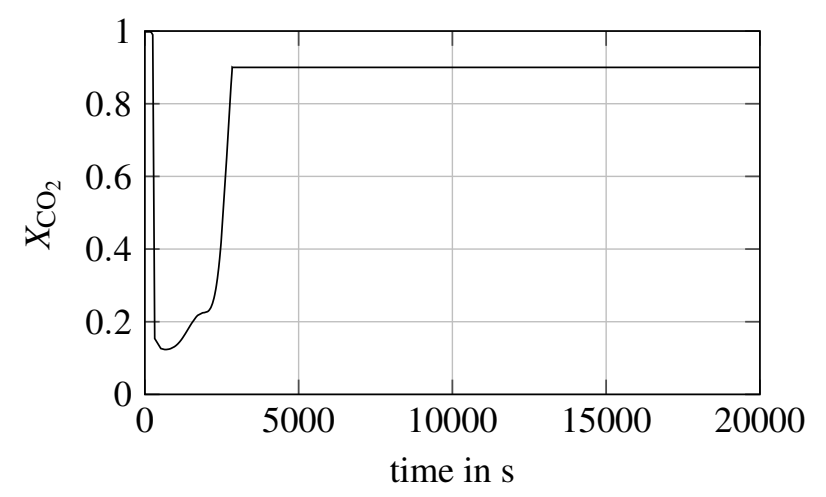

Figure 9. Minimized start-up time - capture rate

The capture rate drops quickly to a very small value of $12 \%$ and increases with increasing solvent flow rate and stripper temperature until a capture rate of $90 \%$ is reached. The start-up time is significantly reduced from $\Delta t=4650 \mathrm{~s}$ to $\Delta t=2840 \mathrm{~s}$. As illustrated in figure 9 , the plant can keep the capture rate of $90 \%$ after the start-up process.

The result of the optimization is a specific optimal solvent flow trajectory for the pilot plant. As the trajectory cannot be applied directly to other plants a more generalized approach for the solvent flow trajectory should be given. Furthermore, the optimal solvent flow trajectory is quite complex since many control actions are required.

To solve this problem a simplified approach based on the optimal solvent flow trajectory is developed. As already mentioned, the solvent flow trajectory can be divided into three phases. Based on this segmentation the recommendations for an optimal start-up scenario are:

1. Set the solvent flow rate to its steady state or maximum possible value to wet the columns.

2. When the columns are wetted and the steam can be supplied from the power plant reduce the solvent flow rate to the lowest possible value.

3. As soon as the reboiler temperature reaches the operation temperature of $120^{\circ} \mathrm{C}$, increase the solvent flow rate to a certain value (in the case of the pilot plant:
$\dot{V}_{\text {liq }}=0.00037 \mathrm{~m}^{3} / \mathrm{s}$ ). The value has to be found by optimizing a model of the certain plant. If this is not feasible another possibility is to control the reboiler temperature with the solvent flow rate by using a PID controller.

4. When the top of the stripper is heated up to $100^{\circ} \mathrm{C}$ set the solvent flow rate to the optimal steady state value (in the pilot plant: $\dot{V}_{l i q}=0.001289 \mathrm{~m}^{3} / \mathrm{s}$ ).

5. Just as the capture rate reaches $90 \%$ switch on the PID controller to keep a constant capture rate.

When applying the simplified start-up strategy to the model, the start-up time increases slightly. However, the implementation of the start-up strategy is a lot simpler. The simplified solvent flow rate derived from the optimization case is presented in figure 10 .

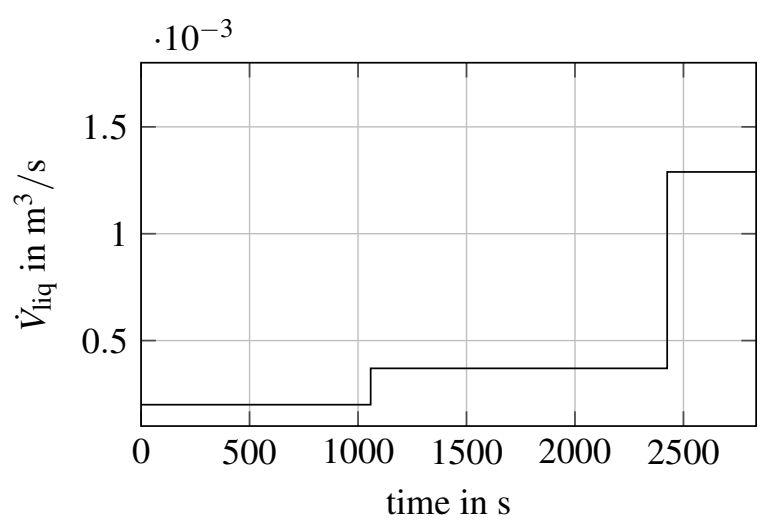

Figure 10. Minimized start-up time - solvent flow rate (simplified)

The result for the carbon capture rate is shown in figure 11. The carbon capture rate increases as expected steeply with increasing solvent flow rate. Between the steps of the solvent flow rate the capture rate increases slightly as the $\mathrm{CO}_{2}$ loading in the stripper sump decreases slowly over time.

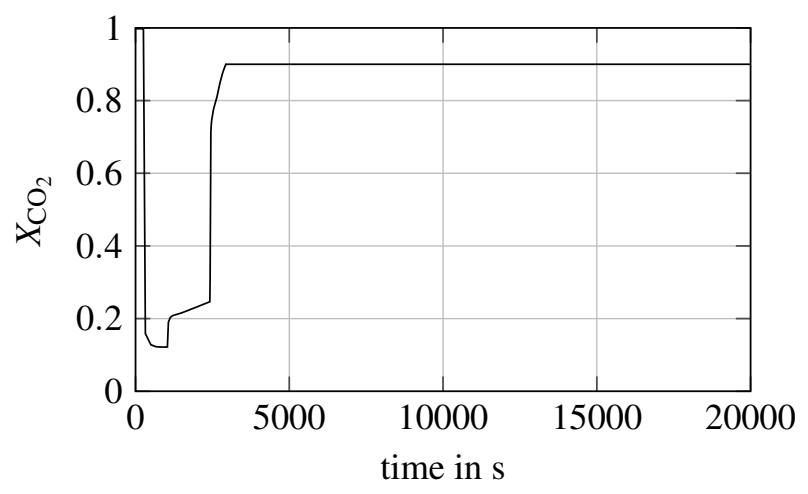

Figure 11. Minimized start-up time - capture rate (simplified)

The start-up time in the simple case increases marginally from $\Delta t=2840 \mathrm{~s}$ to $\Delta t=2939 \mathrm{~s}$. However, the 
implementation of the strategy requires only three control actions of the solvent flow rate during the whole start-up process. The simple approach also offers a high reduction of the start-up time while the constraints are still fulfilled. The reboiler temperature and the liquid hold-up in the reboiler do not exceed their limits at any time.

\section{Maximizing the capture rate}

In a second approach, the main goal is to maximize the mean value of the capture rate during the start-up process (optimization 2). This start-up strategy is useful when low $\mathrm{CO}_{2}$ emissions are more important than a minimal start-up time.

For this optimization run additional constraints have to be determined. The maximum $\mathrm{CO}_{2}$ capture rate is limited to $X_{\mathrm{CO}_{2}}=0.95$ after $t=1000 \mathrm{~s}$ since the carbon capture efficiency is decreasing steeply at very high capture rates. The reason is the very low $\mathrm{CO}_{2}$ partial pressure in the gas phase at very high capture rates. The accuracy of the model decreases in this point of operation. The optimal stationary solvent flow rate is $\dot{V}_{l i q}=0.001289 \mathrm{~m}^{3} / \mathrm{s}$ which is defined as the end point of the trajectory. As the library only handles minimization criteria as presented in equation 3 the mean value of the negative carbon capture rate in a time period of $t=20000 \mathrm{~s}$ is chosen. The additional constraints are shown in table 4 .

The resulting solvent flow rate trajectory of the second optimization run is shown in Figure 12. The trajectory starts at $0.001 \mathrm{~m}^{3} / \mathrm{s}$ and decreases to a minimum at approximately $0.00064 \mathrm{~m}^{3} / \mathrm{s}$. Afterwards the solvent flow rate rises till $0.0016 \mathrm{~m}^{3} / \mathrm{s}$ and drops again until the optimal stationary solvent flow rate of $0.001289 \mathrm{~m}^{3} / \mathrm{s}$ is reached.

Table 4. Additional constraints in optimization run 2

\begin{tabular}{lcl}
\hline Variable name & Criteria & Type \\
\hline Capture rate limit & $X_{\mathrm{CO}_{2}} \leq 0.95$ & anytime \\
Solvent flow rate & $\dot{V}_{l i q}=0.001289 \mathrm{~m}^{3} / \mathrm{s}$ & end point \\
Mean capture rate & $X_{\mathrm{CO}_{2}}$ & maximize \\
\hline
\end{tabular}

The $\mathrm{CO}_{2}$ capture rate in the second optimization run is depicted in figure 13. In comparison with the reference start-up strategy, the capture rate drops quickly to a lower value at the beginning because of the lower solvent flow rate. However, the lower solvent flow rate leads to a faster heat-up in the stripper and regeneration of the solvent. When the solvent flow rate is increased the carbon capture rate increases as well. As a side effect, the start-up time is also in this scenario reduced significantly to $\Delta t=3520 \mathrm{~s}$.

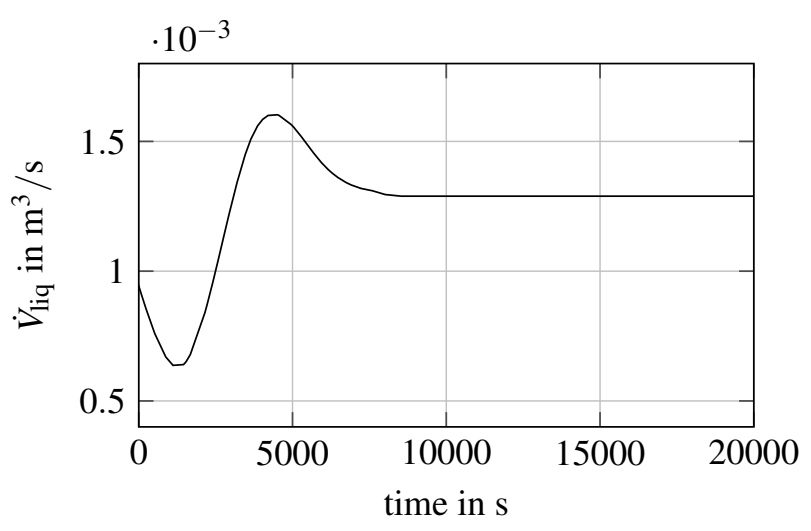

Figure 12. Maximized amount of captured $\mathrm{CO}_{2}$ - solvent flow rate

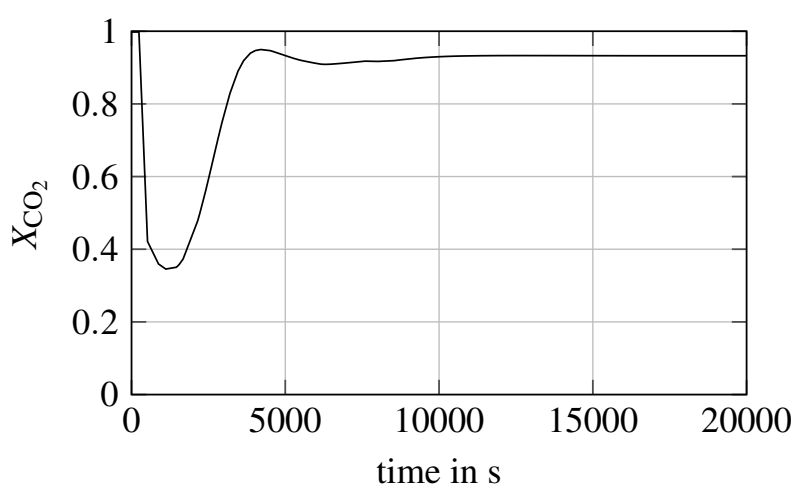

Figure 13. Maximized amount of captured $\mathrm{CO}_{2}$ - capture rate

In table 5 a comparison of the mean capture rate in the different start-up scenarios over the same time period of $t=20000 \mathrm{~s}$ is shown. The minimization of the start-up time is labelled as Optimization 1, the maximization of the mean capture rate is labelled as Optimization 2. The reference strategy is presented in section 5 .

Table 5. Mean value of capture rate in different start-up scenarios

\begin{tabular}{lll}
\hline Reference & Optimization 1 & Optimization 2 \\
\hline 0.836 & 0.805 & 0.856 \\
\hline
\end{tabular}

As expected the highest mean capture rate is achieved in the second optimization run, but the enhancement of the mean capture rate in comparison with the reference startup strategy is quite small. However, the second optimization run leads to a very good compromise between a relatively fast start-up process and a high amount of captured carbon dioxide during the start-up process as the mean capture rate is comparatively small in the first optimization run. In the future, also a multicriteria optimization with the combination of both optimization criteria is conceivable. 


\section{Performance}

The optimization model consists of 29833 equations. As the optimization algorithm can only find local optima one can not guarantee that the best solution has been found. Therefore, the optimization is repeated several times and different start values for the solvent flow rate are used. The result is that the solutions actually are different but they vary only slightly when different start values are used. Sometimes the algorithm does not converge. This is mostly due to the fact that the optimization algorithm cannot evaluate a new solution since the integration of the model fails in some cases. One optimization run takes approximately an average of 18 hours.

\section{Conclusion and Outlook}

The results of this paper show that there is a high optimization potential for the start-up process of a post-combustion capture plant. The start-up time can be significantly reduced by varying the solvent flow rate only.

The results of the model optimization should be applied to the real operation of a carbon capture plant for validation purposes in the future. Unfortunately, the pilot plant used for the validation of the model is no longer in operation.

The optimization does not take thermal stresses in the reboiler into account. Additionally, the reboiler should be discretized in space in order to calculate local temperatures in the reboiler. Both options should be added to the model in the future.

This work focusses on the start-up process at full load. Future work could concentrate on the start-up process at partial load. Furthermore, future optimization should include the variation of other parameters of the plant that influence the start-up process as for example the total amount of solvent. It could be also performed with the used Optimization Library.

The technical design of the pilot plant was not changed during the optimization. Future work should also include the improvement of the technical design. A possible option would be for example the implementation of the lean vapour compression (Fernandez et al., 2012).

The SQP solver used in the optimization does not guarantee that the global optimum is found. The optimization should be also performed by using a genetic algorithm to confirm the results of this paper in the future.

\section{Nomenclature}

$\begin{array}{ll}\alpha & \text { solvent loading }\left(\mathrm{mol}_{\mathrm{CO}_{2}} / \mathrm{mol}_{\mathrm{MEA}}\right) \\ \dot{m} & \text { mass flow rate }(\mathrm{kg} / \mathrm{s}) \\ \dot{N} & \text { molar flow rate }(\mathrm{mol} / \mathrm{s}) \\ \dot{Q} & \text { heat flow rate }(\mathrm{W})\end{array}$

$\dot{V} \quad$ volume flow $\operatorname{rate}\left(\mathrm{m}^{3} / \mathrm{s}\right)$

$N \quad$ amount of substances $(\mathrm{mol})$

$T$ temperature $\left({ }^{\circ} \mathrm{C}\right)$

$t \quad$ time $\mathrm{s}$

$X \quad \mathrm{CO}_{2}$ capture rate (-)

\section{Abbreviations}

$\mathrm{CO}_{2}$ carbon dioxide

CCS carbon capture and storage

MEA monoethanolamine

PCC post-combustion carbon capture

\section{Subscripts}

abs absorber

fg flue gas

in incoming stream

liq liquid

out outgoing stream

reb reboiler

str stripper

sump column sump

\section{References}

A. Pfeiffer. Optimization Library for Interactive Multi-Criteria Optimization. In Proceedings of the 9th International Modelica Conference, pages 669-680. Modelica Association, 2012. doi:10.3384/ecp12076669.

A. Bui, I. Gunawan, V. Verheyen, P. Feron, E. Meuleman, and S. Adeloju. Dynamic modelling and optimisation of flexible operation in post-combustion $\mathrm{CO}_{2}$ capture plants-a review. Computers and Chemical Engineering, 61:245-265, 2014.

Karin Dietl. Equation-Based Object-Oriented Modelling of Dynamic Absorption and Recification Processes. $\mathrm{PhD}$ thesis, Hamburg University of Technology, Hamburg, Germany, 2012.

Eva Sanchez Fernandez, Egbertus J. Bergsma, and Thijs J.H. Vlugt Ferran de Miguel Mercader. Optimization of lean vapour compression (lvc) as an option for post-combustion $\mathrm{CO}_{2}$ capture: Net present value maximisation. International Journal of Greenhouse Gas Control, 11:114 - 121, 2012.

IEA (International Energy Agency). World energy outlook special report: Redrawing the energy-climate map. Technical report, OECD/IEA, France, 2013.

Andreas Joos, Karin Dietl, and Gerhard Schmitz. Thermal Separation: An Approach for a Modelica Library for Absorption, Adsorption and Rectification. In Proceedings of the 7th International Modelica Conference, pages 804-813. Modelica Association, 2009. 
Yu-Jeng Lin, David Shan-Hill Wong, Shi-Shang Jang, and JenqJang Ou. Control strategies for flexible operation of power plant with $\mathrm{CO}_{2}$ capture plant. AIChE J, 58:2697-2704, 2011. doi:10.1002/aic.12789.

Minh Tri Luu, Norhuda Abdul Manaf, and Ali Abbas. Dynamic modelling and control strategies for flexible operation of aminre-based post-combustion $\mathrm{CO}_{2}$ capture systems. International Journal of Greenhouse Gas Control, 39:377-389, 2015. doi:10.1016/j.ijggc.2015.05.007.

Evgenia Mechleri, Adekola Lawal, Alfredo Ramos, John Davison, and Niall Mac Dowell. Process control strategies for flexible operation of post-combustion $\mathrm{CO}_{2}$ capture plants. International Journal of Greenhouse Gas Control, 57:14-25, 2017. doi:10.1016/j.ijggc.2016.12.017.

Rubén M. Montañés, Magnus Korpås, Lars O. Nord, and Stefan Jaehnert. Identifying operational requirements for flexible CCS power plant in future energy systems. Energy Procedia, $86: 22-31,2016$.

Mehdi Panahi and Sigurd Skogestad. Economically efficient operation of $\mathrm{CO}_{2}$ capturing process. Part II. Design of control layer. Chemical Engineering and Processing, 52:112-124, 2011. doi:10.1016/j.cep.2011.11.004.

Johan Åkesson, Carl D. Laird., Geoffry Lavedan., Katrin Prölß, Hubertus Tummescheit, Stephane Velut, and Yu Zhu. Nonlinear Model Predictive Control of a $\mathrm{CO}_{2}$ Post-Combustion Absorption Unit. Chem. Eng. Technol., 35:445-454, 2012. doi:10.1002/ceat.201100480.

Singiresu S. Rao. Engineering Optimization: Theory and Practice. Wiley-VCH, 2009. doi:10.1002/9780470549124.

Alexander Rieder and Sven Unterberger. EnBW's postcombustion capture pilot plant at Heilbronn - Results of the first year's testing programme. Energy Procedia, pages 1553$1571,2013$.

United Nations, Framework Convention on Climate Change. Report of the Conference of the Parties on its twenty-first session, held in Paris from 30 November to 13 December 2015, 2016.

VFF GmbH. Manufacturer of random packings for pilot plant, 2016. URL http://http://www.vff.de/en/ products/random-packings.

Kai Wellner, Thomas Marx-Schubach, and Gerhard Schmitz. On the dynamic behaviour of coal fired power plants with post-combustion $\mathrm{CO} 2$ capture. Industrial \& Engineering Chemistry Research, 55(46):12038-12045, 2016. doi:10.1021/acs.iecr.6b02752. 